\title{
Fabrication of Chimney Cleaning System
}

\author{
Suresh $\mathrm{Y}^{1}$, Pramod $\mathrm{V}^{2}$, Raghavendra Prabhu ${ }^{3}$, Nikhil L ${ }^{4}$ \\ ${ }^{I}$ Assistant Professor, Department of Mechanical Engineering, DBIT, India \\ ${ }^{2,3,4}$ UG Scholars, Department of Mechanical Engineering, DBIT, India
}

\begin{abstract}
In today's scenario, small scale and large scale industries, hotels, restaurants and houses use chimneys in maximum quantity because of their needs. Due to continuous usage, the chimney surfaces will get covered with soot particles, oil, grease, etc. Nowadays these contaminants are removed using vibrating wire brushes and vacuum cleaners. But this may affect the surface integrity and the cleaning is not up to a satisfactory level. It is difficult to reach all the corners of the chimney and to reach the complete height of the chimney for cleaning. By keeping all these parameters, in this investigation we plan to fabricate a chimney cleaning machine for different applications. Pump is to be modified in such a way that it should not react with the chemicals used in cleaning process, by selecting a proper material. The machine is fabricated with minimum joining processes. After the fabrication, the machine is successfully working on expected condition to remove the dust particles, oil and grease from the surface completely without affecting the surface integrity. It is cleaning efficiently and effectively. It can clean each and every corner of the chimney and it can cover the entire height of the chimney.
\end{abstract}

Keywords: Pump, Chimney, Nozzle, Water Heater, Hose.

\section{Introduction}

A Chimney is structure, which provides exit for hot flue gases or smoke from a boiler, furnace to the atmosphere. Generally they are vertical or almost possible vertical structure to ensure that the gases flow smoothly, drawing air into the combustion in what is known as the stack or chimney effect. The Industrial chimneys are usually made of metals as shown ig fig. 1 . They are also called metal chimneys. These chimneys find wide application in different manufacturing industries, made of different metals like stainless steel, aluminium or galvanized iron. These have better thermal and mechanical properties compared to masonry chimneys. Chimney cleaning is necessary to remove soot, blockages and built-up creosote from your chimney liner, firebox, smoke in chamber and dampers. Physical contact with creosote build-up can cause rashes and other major skin and eye irritation. we have different methods to clean the chimney like Vibrator, Wire brush. By using all these methods Chimney's can be cleaned but not cleaned efficiently and effectively and also it damages the surface. So in this investigation Pump is modified for our requirement like to withstand high temperature and chemical resistant. then high pressure, high temperature water is sprayed on to the surface of the chimney.

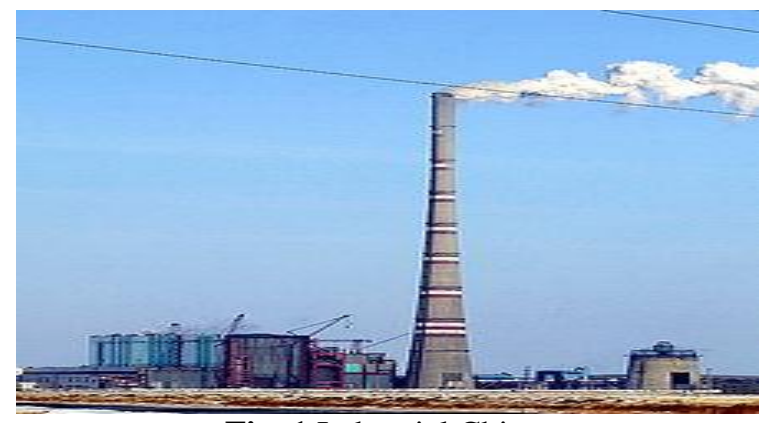

Fig. 1 Industrial Chimney

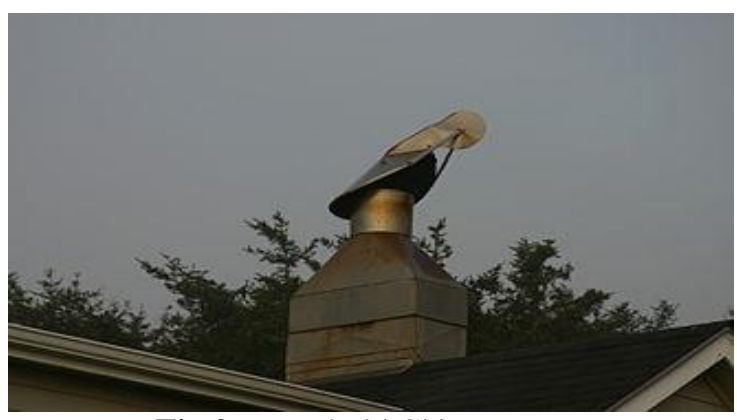

Fig.2 Household Chimney

\subsection{Parts of Chimney}

The following are the parts of chimney as shown in fig. 3 .

\subsubsection{Flue}

A flue is simply a passage for conveying exhaust gases from an appliance to the outdoors. A flue may duct, pipe, vent, or chimney. 


\subsubsection{Flue Lining}

For a safe flue, a lining must be used to ensure minimal accumulation of flammable debris. This lining should be stainless steel or specially formulated lining tile.

\subsubsection{Smoke Chamber}

The purpose of the smoke chamber is to gently compress the by products of combustion into a smaller space without causing back draft. The use of sloping walls, in conjunction with good fireplace design and maintenance, helps facilitate this.

\subsubsection{Chimney Damper}

Chimney Dampers are lever or pulley activated doors within your chimney. They can be closed to prevent energy loss when your fireplace isn't being used. They also help prevent rain water or animals from entering your home if your chimney cap doesn't restrict this.

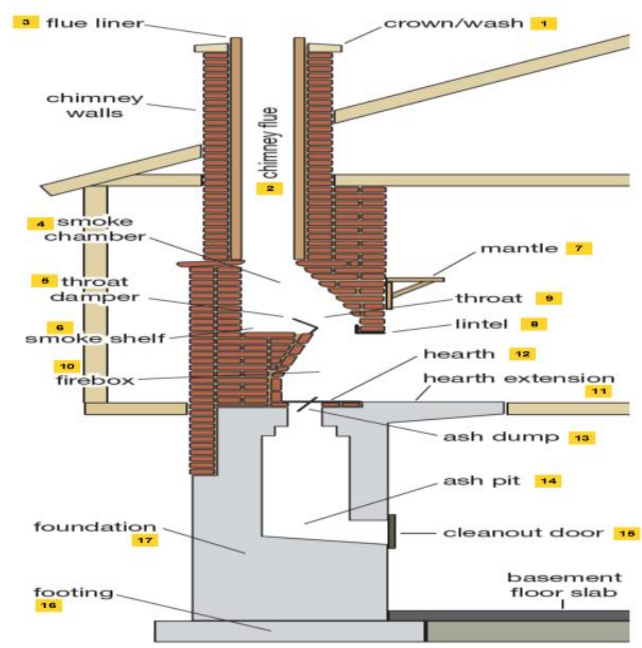

Fig. 3 Parts of chimney

\subsection{Need for chimney cleaning}

Chimney cleaning is necessary to remove soot, blockages and built-up creosote from your chimney liner, firebox, smoke chamber and damper. This cleaning will help or create a safer operation of your system during the working condition. It takes only a small accumulation of creosote glazing to create the potential for a chimney fire. Creosote is a highly flammable substance that builds up inside your chimney or liner as a result of burning wood as shown if fig. 4 . The rate of accumulation can be higher if there is a practice of poor burning or a burning appliance or stove that is not working well. Different types of wood create different amounts of creosote when burned. Pine causes a rapid build-up of creosote and should be avoided as a regular source of wood. Creosote can also reduce the draw of the fireplace and reduce efficiency.

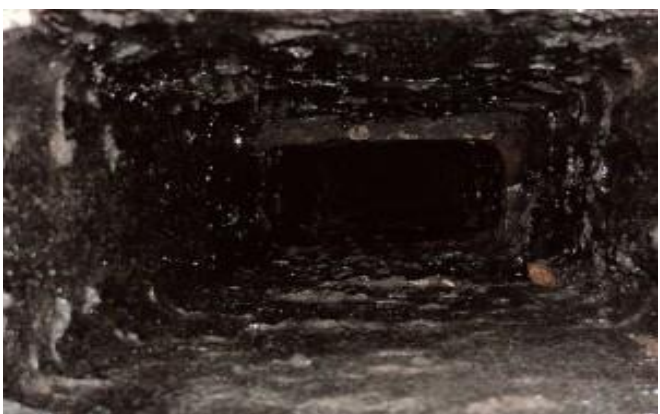

Fig. 4 Creosote deposit on chimney

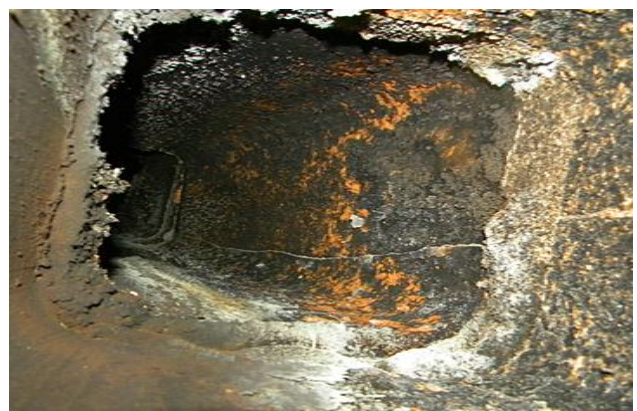

Fig.5 Soot deposits on chimney

\subsection{Drawbacks of the methods followed to clean chimney}

- Although there are methods available there isn't much advancement in the procedures followed for cleaning the chimney.

- The cleaning obtained by following the stated methods are not satisfactory and it involves lot of labour costs. 
- The professionals who clean the chimney are also often at health risks due to inhailing of hazardous pollutants

- The wire brushes used to clean chimneys affect the surface integrity of chimney.

- The chimney sweep vacuum cleaners cannot effectively absorb the pollutants at higher heights.

\section{Methodology}

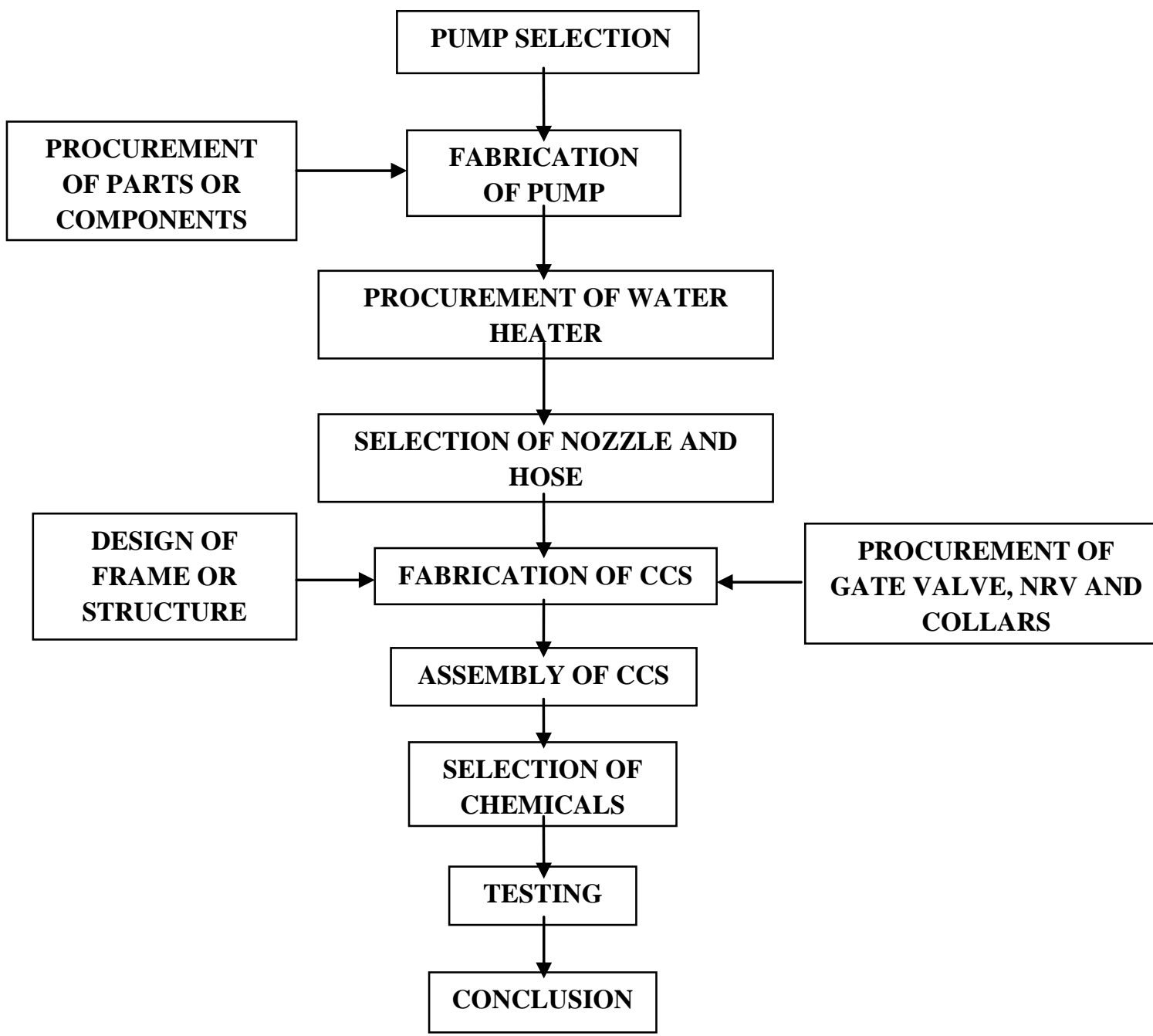

In this investigation the chimney cleaning system is fabricated. The pump is modified in such a way that the effect of hot water and chemicals should not corrode the surface of the pump component parts like shaft, Impeller and casing, hence precautionary measures were considered while modifying the pump. The impeller available in present market for our requirement is Pp virgin Impeller, where it can withstand high temperature and also chemical resistant. After selecting the impeller casing for inlet and outlet are modified in such a way to get the desired pressure at the outlet as per requirement. Suction and delivery part are coated with the Polyurethane coating, which is a good chemical resisting and also withstands high temperature. Then stainless steel water heater is procured, which is good chemical resistant. the hose and nozzle are procure as per the condition that it has to withstand the high temperature of water and it should not react with the high temperature water and also chemical reaction with the components. the hose is made up of EPDM. Nozzle selected with two flow condition. The structure is designed in such a way to get total system in a compact manner. One non return valve is used at the suction part of the pump. Then the total assembly is subjected to testing.

\section{PUMP}

A Pump is a device that converts mechanical energy to Fluid energy in order to raise the water from lower head to high head by pressurizing it. The pump available in the market cannot efficiently pump the chemicals without corroding the impellers and other components. Hence we have modified a pumping system which can transport high temperature water and chemicals without corroding its impeller and inner sections. The impeller 
within the pump system available in the market are made of bronze material, these bronze impellers will corrode for chemicals. So we have selected Polypropylene is an economical material that offers a combination of outstanding physical, chemical, mechanical, thermal and electrical properties, which are not found in any other thermoplastic. Compared to low or high density polyethylene, it has a lower impact strength, but superior working temperature and tensile strength.

Table 1: Properties of Polypropylene

\begin{tabular}{|l|l|}
\hline Physical Properties & Value \\
\hline Tensile Strength & $0.95-1.30 \mathrm{~N} / \mathrm{mm}^{2}$ \\
\hline Notched Impact Strength & $3.0-30.0 \mathrm{~kJ} / \mathrm{m}^{2}$ \\
\hline Thermal Coefficient of Expan & $100-150^{*} 10^{-6}$ \\
\hline Max. Continued Use Tempera & $80^{\circ} \mathrm{C}\left(176^{\circ} \mathrm{F}\right)$ \\
\hline Melting Point Temperature & $160^{\circ} \mathrm{C}\left(320^{\circ} \mathrm{F}\right)$ \\
\hline Glass Transition Temperature & $-20^{\circ} \mathrm{C}\left(-4^{\circ} \mathrm{F}\right)$ \\
\hline Glass Transition Temperature & $100^{\circ} \mathrm{C}\left(212^{\circ} \mathrm{F}\right)$ \\
\hline Density & $0.905 \mathrm{~g} / \mathrm{cm}^{3}$ \\
\hline
\end{tabular}

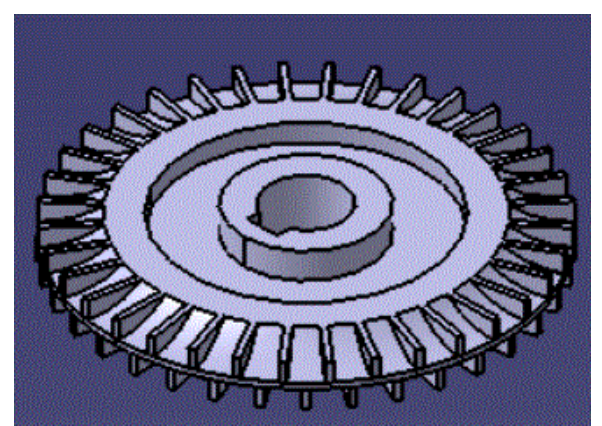

Fig. 6 Conventional Bronze Impeller

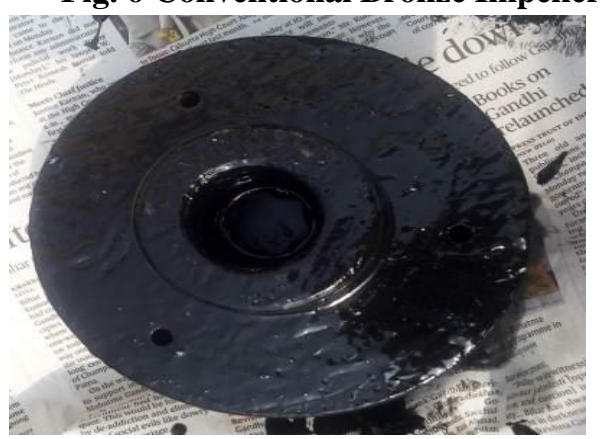

Fig.8 Fabricated inlet section

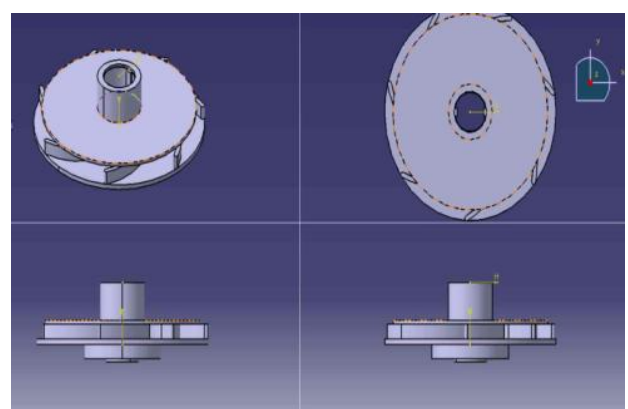

Fig. 7 PP Virgin Impeller

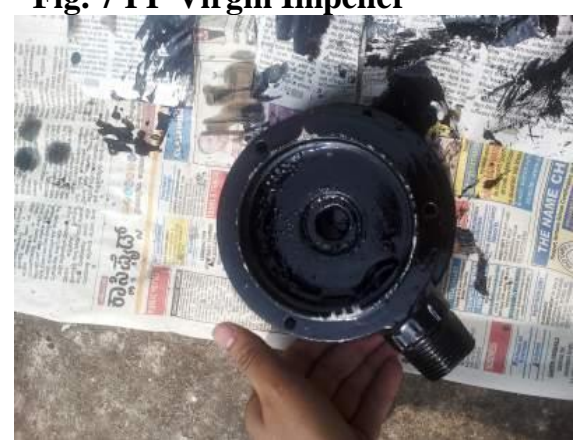

Fig. 9 Fabricated delivery section

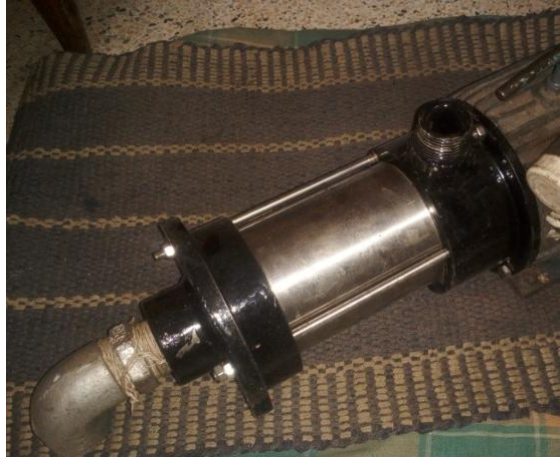

Fig. 10 Modified pump

\section{Water Heater}

The water heater is a device used for heating water. Here the water heater used has a capacity of 30liters, it is made up of stainless steel. Stainless steel material is used in order to withstand chemical reaction and avoid corrosion. The heating element is bronze. Bronze material is chosen due to its lower cost and availability in the market and easy replacement. The heater has been procured. 
Table 5.1: Specifications of the water heater

\begin{tabular}{|c|c|}
\hline Material & Stainless Steel \\
\hline Heating Element & Bronze \\
\hline Overall Height & 18.6 inch \\
\hline Outer Diameter & 13.7 inch \\
\hline Inner Diameter & 13.6 inch \\
\hline Power Consumption & $4000 \mathrm{~W}$ \\
\hline Capacity & 30 litres \\
\hline
\end{tabular}

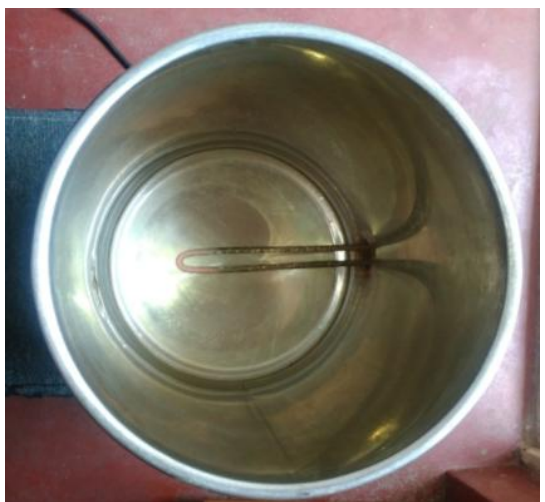

Fig. 11 Top View of heater

\section{Structure Design}

The entire chimney cleaning system is mounted on a trolley. A provision is made to seat the boiler at the base and pump another protruded plate is welded to fix the pump and hoses and valves are connected to pump and boiler suitable hooks are provided behind the trolley to hang pipes. Flexible wheels are provided to move the weighed trolley in multi-directions.

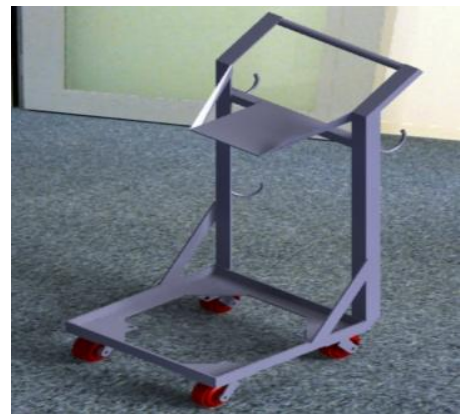

Fig. 12: Structure Design

\section{Assembly Of Chimney Cleaning System}

In the assembly of chimney cleaning system boiler is kept on a trolley, which is chained to a hook of the trolley. Pump is mounted on a shelf supported with suitable angle plates as shown in fig. The outlet of the pump is controlled by a gate valve, one end of the gate valve which acts as excess flow line is connected to boiler and the other end of the gate valve is connected to nozzle handle assembly through flexible hosing, the inlet of the pump is connected to bottom of the boiler with suitable collars. The inlet pipe is connected to foot valve which helps in suction of water from the boiler.

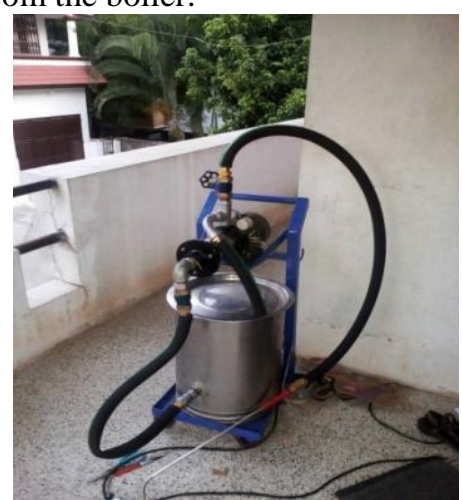

Fig. 13: Assembly of chimney cleaning system 


\section{Results And Discussion}

The initial stage begins with water addition to the heater and covering the furnace to prevent entry of water. On addition of water to heater, the heater is closed with the lid and power connections are made to the heater. Heating process is carried on for about 10mins duration, further the water is pumped at high pressure into the chimney surface by mist spray nozzle. The chemical is added to the heater in suitable proportions. This is followed by acid pickling process where the acid is sprayed on the chimney layer by the nozzle. Further the chimney with the chemical sprayed on it is left for about $15 \mathrm{mis}$ for chemical to react with the pollutants of the chimney. The chemical mixed with water is added in right proportions to the heater and heated again, and this mixture is pumped into the chimney surface with a jet nozzle at high pressure which removes the oil, grease and other pollutants adhered to the chimney surface thereby cleaning it and increasing the efficiency of the chimney.

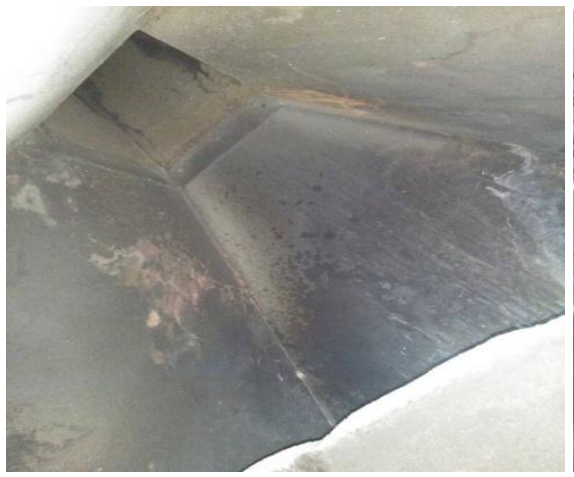

Fig. 14: Chimney before cleaning

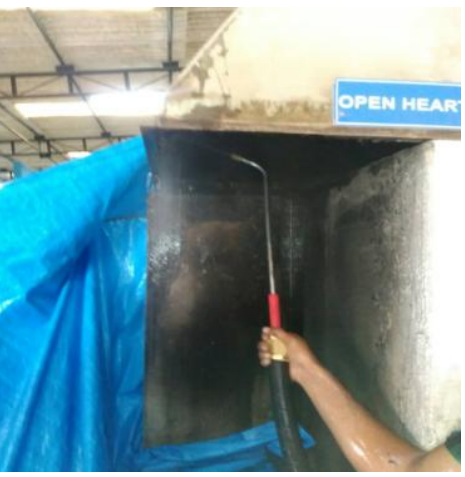

Fig. 15: Cleaning with chemicals

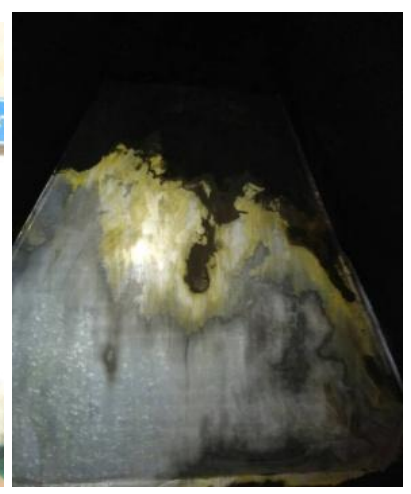

Fig.16: Cleaned surface

\section{Conclusion}

$\checkmark \quad$ The machine can subject to work for different capacity pumps with different flow conditions.

$\checkmark \quad$ The machine is working satisfactorily under different flow condition.

$\checkmark$ High head chimneys can be cleaned effectively without damaging the surfaces.

$\checkmark$ Pump satisfactorily working with different proportion of chemicals.

$\checkmark$ Different nozzles can be used for different flow conditions.

$\checkmark$ Time duration for cleaning the chimney when compared with that of traditional methods is less.

$\checkmark$ Different impellers can be implemented to the pump to check the working condition with the chemicals and high temperature water.

$\checkmark \quad$ larger water heaters can be implemented to clean the large industrial chimneys and other applications.

$\checkmark$ Pump can be inspected to different chemical working conditions.

\section{Acknowledgement}

I would like to express my profound gratitude to Dr. R PRAKASH, Principal, Don Bosco Institute of Technology, Bengaluru, for permitting me to carry out this project. I am grateful to Mr. SHIVANNA, Professor $\&$ Head of the Department, Mechanical Engineering, DBIT., Bangalore, for his cheerful encouragement and valuable suggestions. I would also like to acknowledge the effort put in by my guide, in helping me to understand the relevant concepts and providing guidance when necessary. I express my deep sense of gratitude to Mr. P B MANJUNATH, Vice president and Mr. RAGHAV BYLAPPA, Secretary, Don Bosco Institute of Engineering and Technology, Bangalore for their support and motivation. Last but not the least I express my gratitude to my parents and all my friends who helped in one-way or the other.

\section{Reffrences}

[1] Dr.Manoj Kr Gupta, Dr.V K Bajpai, Dr.T K Garg, "Latest Measures to Keep Chimneys in Step with Plant Changes", International Journal of Engineering Research and Technology (IJERT), ISSN: 2278-0181 Vol.3 Issue 5, May - 2014

[2] Aleksandar M. Simonovic, Slobodan N. Stupar, Ognjen M. Pekovic, "Stress Distribution as a Cause of Industrial Steel Chimney Root Section Failure", Faculty of Mechanical Engineering, Belgrade, Vol.36 No 3, 2008.

[3] Prof.Wakchaure M.R., Sapate S.V, Kuwar B.B. , Kulkarni P.S. , "Cost Optimization of Reinforced Concrete Chimney", International Journal of Civil Engineering and Technology (IJCIET), Vol.4 Issue 2, March - April (2013), pp. $402-414$.

[4] Heat Rate Improvement Reference Manual, EPRI, Palo Alto, CA: 1998. TR-109546 5. Energy and Efficiency managementsystem by NTPC.

[5] Virendra Nagar, Dr. V. K. Soni, Dr. V. K. Khare, Boiler Efficiency Improvement through Analysis of Losses IJSRD

[6] George P. Sutton and Oscar Biblarz, "Rocket Propulsion Elements", A Wiley- Interscience Publication, Seventh Edition, 2001,(pp 1-99).

[7] K.Ramamurthi, "Rocket Propulsion”, Macmillan publishers India, 2012 edition, (pp 54-89).

[8] K.M.Pandey and S.K.Yadav, "CFD Analysis of a Rocket Nozzle with Two Inlets at Mach 2.1", Journal of Environmental Research and Development, Vol 5, No 2, 2010, (pp 308-321). 
[9] Biju Kuttan P and M Sajesh, "Optimization of DivergentAngle of a Rocket Engine Nozzle Using Computational Fluid Dynamics", The International Journal Of EngineeringAnd Science (Ijes), Volume 2, No 2, 2013, pp 196-207.

[10] Batham, J.P., "Parameters required for the wind-tunnel simulation of the wind loads on large power station chimneys", Wind Engineering and Industrial dynamics, Elsevier science publishers -Amsterdam, Vol.18, 1985, pp.75-90.

[11] Milford R.V., "Structural reliability and cross windresponse of tall chimneys". Engineering structures, Butterworth \& Co. (Publishers) Ltd, Vol.4, 1982, pp.263-270.

[12] Reddy K.R.C, Jaiswal O.R and Godbole P.N, "Wind response control of tall RC chimneys", Wind and Engineering, Vol. 8, 2011, pp. $1-9$.

[13] Reddy K. R. C, Jaiswal O. R. and P. N. Godbole.,"Wind and Earthquake Analysis of Tall RC Chimneys", Earth sciences and Engineering, October 2011, pp. 508-511.

[14] Vickery B.J. and Basu.R. "Simplified approaches to the evaluation of the across wind Response of chimneys", Wind Engineering and Industrial dynamics, Elsevier science Publishers -Amsterdam, 1983, pp. 153-166

[15] Code of practice for design loads for buildings andstructures, IS: 875(Part-III):1987, published by Bureauof Indian standards.

Suresh Y. "Fabrication of Chimney Cleaning System." IOSR Journal of Mechanical and Civil Engineering (IOSR-JMCE) 14.4 (2017): 23-29. 